\title{
Lactobacillus plantarum G72 Showing Production of Folate and Short-chain Fatty Acids
}

\author{
Hye Ji Jang, Na-Kyoung Lee, and Hyun-Dong Paik* \\ Department of Food Science and Biotechnology of Animal Resources, Konkuk University, Seoul 05029, Republic of Korea
}

Received: September 25, 2020 / Revised: November 6, 2020 / Accepted: December 11, 2020

\begin{abstract}
The aim of this study was to determine the production of folate, short chain fatty acids (SCFAs), and antimicrobial activity exhibited by Lactobacillus plantarum G72 for potential dietary application in pregnant women. L. plantarum G72 has been reported to possess characteristic activities and functionality including $\beta$-galactosidase activity and antioxidant activities. L. plantarum G72 showed antibacterial activity against pathogenic bacteria (Listeria monocytogenes ATCC 15313, Salmonella typhimurium P99, Escherichia coli ATCC 25922, and Staphylococcus aureus KCCM 11335) using a modified method, and formation of the largest inhibition zone was observed against $S$. aureus KCCM $11335(12.0-17.0 \mathrm{~mm})$. The adherence of four food-borne pathogenic bacteria to HT-29 cells was inhibited by L. plantarum G72 (0.13 to $0.92 \mathrm{log}$ CFU/ml). The most considerable inhibition of adherence to HT-29 cells was observed by using L. plantarum G72 against $S$. typhimurim P99. Additionally, folate production by $L$. plantarum $\mathrm{G72}$ was $50.1 \mathrm{ng} / \mathrm{ml}$, and $L$. plantarum G72 produced relatively more lactic acid $(11,176.73 \mathrm{mg} / \mathrm{kg})$ than acetic, propionic, or butyric acids. Therefore, the results of this study suggest that L. plantarum G72 may serve as a multifunctional food additive in the health industry.
\end{abstract}

Keywords: Probiotics, Lactobacillus plantarum, antimicrobial activity, folate, short-chain fatty acids

\section{Introduction}

Probiotics are defined as "live micro-organisms", when administered in adequate amounts to the host, confers a health benefit [1-3]. Probiotics should be able to tolerate the gastric condition of the gastrointestinal (GI) tract and reach the small intestine and adhere to human epithelial surfaces [4, 5]. Probiotics have various beneficial effects including antioxidant, anti-allergic, anticancer, cholesterol reduction, diarrhea prevention, and immune function enhancing activities [5-7]. Especially, probiotic microorganism is important to link to the gastrointestinal tract. The digestive viability and antimicrobial effects of probiotics are influenced by $\mathrm{pH}$, acidity, temperature, removed hydrogen, and oxygen peroxide [9].

*Corresponding author

Tel: +82-2-2049-6011

E-mail:hdpaik@konkuk.ac.kr
Folate (vitamins $B_{9}$ ), is required for body function to repair and synthesize DNA [10], and is important for basic physiological mechanisms [11]. Therefore, folate is required not only for most people but also for pregnant women as a health functional food. Especially, pregnant women are advised to increase their folate intake as folate helps in the production of red blood cell and development of the brain and the spinal cord, thus, a sufficient of folate could promote fetal growth and development [12]. Recently, an interesting study about folate production by probiotic has been reported [13]. Lactobacillus sakei strains have indicated that the highest folate produced 730-1,484 ng/g [14]. In addition, probiotics could help absorb folate through the intestinal lining according to a research that reports intestinal microbiota to be a source of vitamins [15].

Short-chains fatty acids (SCFAs) contain fewer than six carbons, exist in straight and branched-chains [16]. Acetic acid, propionic acid, and butyric acid are reported 
to be the most important SCFAs. SCFAs are produced by bacteria in the GI tract and these bacteria use nondigestible carbohydrates (NDC) as their main energy source [17, 18]. Especially, production of SCFAs is important to make the intestinal environment more acidic, thereby inhibiting the colony of pathogenic microorganisms [18]. Moreover, they have various functions, including anti-inflammatory, antifungal, and anti-obesity effects [20, 21].

In previous study, Lactobacillus plantarum G72 was isolated from kimchi and identified as L. plantarum by 16S rRNA sequencing [7]. L. plantarum G72 has been reported to have characteristic activities such as tolerance to artificial gastric conditions, enzyme production, antibiotic sensitivity, and adhesion to HT-29 cells. In addition, $L$. plantarum G72 of $\beta$-galactosidase activity and antioxidant activities that have been established through the DPPH free radical scavenging assay (21.08\%) and the $\beta$-carotene bleaching assay (31.92\%). Thus, the aim of this study was to investigate production of folate, SCFAs and antimicrobial activity by L. plantarum G72 for pregnant women.

\section{Materials and Methods}

\section{Bacterial strains and culture conditions}

L. plantarum G72 was isolated from kimchi and Lactobacillus rhamnosus GG (LGG) was obtained from the Korean collection for type cultures (Jeolla-do, Korea). They were grown in lactobacilli MRS broth (BD BBL, USA) at $37^{\circ} \mathrm{C}$ for $15 \mathrm{~h}$. LGG was used as a commercial probiotic strain. Escherichia coli ATCC 25922, Listeria monocytogenes ATCC 15313, Salmonella Typhimurium P99, and Staphylococcus aureus KCCM 11335 as foodborne pathogenic bacteria were grown in tryptic soy broth (TSB; Becton-Dickinson, USA) at $37^{\circ} \mathrm{C}$ for $24 \mathrm{~h}$.

\section{Hemolytic activity}

L. plantarum G72 and LGG were streaked onto Columbia agar containing $5 \%$ (w/v) sheep blood and cultured at $37^{\circ} \mathrm{C}$ for 24 h. L. plantarum G72, LGG, and foodborne pathogenic bacteria were expressed for signs of $\beta$ hemolysis (clear zones around colonies), $\alpha$-hemolysis (green-hued zones around colonies) or $\gamma$-hemolysis (no clear zones around colonies), respectively.

\section{Antimicrobial activity}

L. plantarum G72 was assessed for antimicrobial activity against four food-borne pathogenic bacteria $(L$. monocytogenes ATCC 15313, S. Typhimurium P99, E. coli ATCC 25922, and S. aureus KCCM 11335) with modifications [7, 8]. To identify the antimicrobial activity, $3 \mu \mathrm{l}$ of Lactobacillus strains was spotted on MRS agar and incubated at $37^{\circ} \mathrm{C}$ for $24 \mathrm{~h}$. Then, $4 \mathrm{ml}$ of TSB soft agar containing $100 \mu \mathrm{l}$ of the indicator food-borne pathogenic bacteria $\left(10^{6} \mathrm{CFU} / \mathrm{ml}\right)$ was overlaid and incubated at $37^{\circ} \mathrm{C}$ for $24 \mathrm{~h}$. The diameters $(\mathrm{mm})$ of the clear zones were measured.

\section{Inhibition of adherence of food-borne pathogenic bacte- ria to HT-29 cells}

Inhibitory activity of adherence of food-borne pathogenic bacteria was determined with a modified deferred method reported in Jeon et al. [9]. HT-29 cells $\left(1 \times 10^{5}\right.$ cells/well) were seeded into 24 -well plates and incubated at $37^{\circ} \mathrm{C}$ for $24 \mathrm{~h}$. About $10^{6} \mathrm{CFU} /$ well of food-borne pathogenic bacteria with or without $L$. plantarum G72 were added and incubated at $37^{\circ} \mathrm{C}$ for $2 \mathrm{~h}$. Plates were washed twice with phosphate buffered saline (HyClone, USA) to remove non-adherent cells. To detach HT-29 cells, $1 \mathrm{ml}$ of $1 \%(\mathrm{v} / \mathrm{v})$ Triton X-100 solution added to 24 -well plates. The mixture was spread on Oxford (Becton-Dickinson), xylose lysine desoxycholat (XLD; Becton-Dickinson), eosine methylene blue (EMB; Becton-Dickinson), and mannitol salt agar (MSA; Becton-Dickinson) for E. coli, L. monocytogenes, S. Typhimurium, and S. aureus, respectively, to measure viable cells.

\section{Production of folate}

To identify the production of folate, L. plantarum G72 and LGG were cultured on MRS broth at $37^{\circ} \mathrm{C}$ for $15 \mathrm{~h}$. The Lactobacillus strains were centrifuged at $14,240 \times \mathrm{g}$ for $10 \mathrm{~min}$ and the supernatants were filtered through a membrane filter $(0.45 \mu \mathrm{m})$. Production of folate was identified using folic acid ELISA kit (Cell Biolabs INC, USA).

\section{Short-chain fatty acids analysis}

Sample preparation. To analyze the production of short-chain fatty acids (SCFAs), Lactobacillus strains were cultured on MRS broth containing $2 \%$ arabinose at 
$37^{\circ} \mathrm{C}$ for $15 \mathrm{~h}$. The Lactobacillus strains were centrifuged at $14,240 \times g$ for $10 \mathrm{~min}$ and the supernatants were filtered through a membrane filter $(0.2 \mu \mathrm{m})$.

HPLC analysis. HPLC was measured using Agilent 1100 system (Agilent Technologies, USA). The column was a reverse phase with Hypersil GOLD aQ column (4.6 mm $\times 150 \mathrm{~mm}, 5 \mu \mathrm{m}$ ) (Thermo Fisher Scientific, USA). The elution was used with $50 \mathrm{mM}$ potassium phosphate buffer ( $\mathrm{pH} 2.8$ ) with a $1.25 \mathrm{ml} / \mathrm{min}$ flow rate and $20 \mu \mathrm{l}$ of injection volume. UV absorbance was measured at $210 \mathrm{~nm}$. The standards of SCFAs including lactic acid, acetic acid, propionic acid, and butyric acid were purchased from Sigma-Aldrich (Germany). All samples were filtered through a membrane filter $(0.2 \mu \mathrm{m})$ and then HPLC was measured.

\section{Statistical analysis}

All experiments were conducted in triplicates and are presented as the mean \pm standard deviation. Significant differences among the means were determined by oneway analysis of variance (ANOVA) and Duncan's multiple range test. Significant difference between two groups was determined by Student's t-test (SPSS software version 19; IBM, USA). The values were considered statistically significant for $p<0.05$.

\section{Results and Discussion}

\section{Hemolytic activity}

The hemolytic activity is known for a safety aspect for

Table 1. Hemolytic activity of probiotic and food-borne pathogenic bacteria.

\begin{tabular}{lccc}
\hline & \multicolumn{3}{c}{ Hemolytic activity ${ }^{1)}$} \\
\cline { 2 - 4 } Microorganisms & $\begin{array}{c}\alpha- \\
\text { Hemolysis }\end{array}$ & $\begin{array}{l}\beta^{-} \\
\text {Hemolysis }^{-}\end{array}$ & $\begin{array}{c}\gamma^{-} \\
\text {Hemolysis }\end{array}$ \\
\hline Lactic acid bacteria & - & - & - \\
L. rhamnosus GG & - & - & - \\
L. plantarum G72 & & & \\
Food-borne pathogenic bacteria & & + & - \\
E. coli ATCC 25922 & - & + & + \\
L. monocytogenes ATCC 15313 & - & - & - \\
S. Typhimurium P99 & + & - & - \\
S. aureus KCCM 11335 & - & + & - \\
\hline
\end{tabular}

${ }^{11}+$, positive; -, negative.
Table 2. Antimicrobial activity of $L$. rhamnosus GG and $L$. plantarum $\mathrm{G72}$ against food-borne pathogenic bacteria by deferred method.

\begin{tabular}{lcc}
\hline \multirow{2}{*}{ Food-borne pathogenic bacteria } & \multicolumn{2}{c}{ Inhibitory diameter (mm) } \\
\cline { 2 - 3 } & \multicolumn{1}{c}{ L. } & L. plantarum \\
& rhamnosus GG & G72 \\
\hline Escherichia coli ATCC 25922 & $13.33 \pm 0.58^{\mathrm{Aa}}$ & $12.00 \pm 2.83^{\mathrm{Ab}}$ \\
Listeria monocytogenes ATCC 15313 & $15.00 \pm 0.00^{\mathrm{Aa}}$ & $12.00 \pm 2.00^{\mathrm{Ab}}$ \\
Salmonella Typhimurium P99 & $2.33 \pm 0.58^{\mathrm{Bb}}$ & $13.67 \pm 1.15^{\mathrm{Aab}}$ \\
Staphylococcus aureus KCCM 11335 & $15.00 \pm 1.73^{\mathrm{Aa}}$ & $17.00 \pm 2.65^{\mathrm{Aa}}$ \\
\hline
\end{tabular}

All values are mean \pm standard deviation.

${ }^{A-B}$ The superscript upper-case letters in the same row indicate statistical differences by Student's t-test $(p<0.05)$.

${ }^{a-c}$ The superscript lower-case letters in the same column indicate statistical differences by ANOVA $(p<0.05)$.

the requirement of probiotic strains [23]. Plates were tested for hemolysis sign, which is expressed $\alpha$-hemolysis (green zones), $\beta$-hemolysis (clear zones), and $\gamma$-hemolysis (no-clear zones). However, S. aureus KCCM 11335 indicated $\alpha$-hemolysis and $S$. Typhimurium P99 and $E$. coli ATCC 25922 indicated $\beta$-hemolysis. Therefore, $L$. plantarum G72 should be non-pathogenic and indicated as safe organism for human health in Table 1.

\section{Antimicrobial activity}

The antimicrobial activity of $L$. plantarum G72 was showed in Table 2. L. plantarum G72 exhibited distinct antimicrobial activity against $E$. coli ATCC 25922, L. monocytogenes ATCC 15313, S. Typhimurium P99, and S. aureus KCCM 11335. S. aureus KCCM 11335 demonstrated the largest inhibition zone $(17 \mathrm{~mm})$. One study demonstrated that Lactobacillus sp. (LBS 8) isolated dairy samples showed the highest inhibition zone (14 mm) against $S$. aureus [24]. L. plantarum DM69 also exhibited a clear zone of more than $15 \mathrm{~mm}$ against foodborne pathogenic bacteria [25]. In addition, various researches have reported the antimicrobial activity of Lactobacillus sp. against Salmonella sp. Another study has reported the antimicrobial activity of Enterococcus durans against L. monocytogenes, $E$. coli, and $S$. Typhimurium [23]. The antimicrobial activity is due to the production of metabolites such as organic acids, hydrogen peroxide, bacteriocin, and other compounds that have inhibitory properties [23, 24]. 
Table 3. Inhibition activity of L. plantarum G72 against adherence of food-borne pathogenic bacteria to HT-29 cells.

\begin{tabular}{lcc}
\hline & \multicolumn{2}{c}{ Adherent cell no. (Log CFU/ml) } \\
\cline { 2 - 3 } Food-borne pathogenic bacteria & $\begin{array}{c}\text { Food-borne } \\
\text { pathogenic } \\
\text { bacteria }\end{array}$ & $\begin{array}{c}\text { Food-borne } \\
\text { pathogenic } \\
\text { bacteria with } \\
\text { L. plantarum G72 }\end{array}$ \\
\hline Escherichia coli ATCC 25922 & $6.74 \pm 0.24^{\mathrm{Ab}}$ & $6.57 \pm 0.14^{\mathrm{Ab}}$ \\
Listeria monocytogenes ATCC 15313 & $4.78 \pm 0.11^{\mathrm{BC}}$ & $5.45 \pm 0.21^{\mathrm{Ac}}$ \\
Salmonella Typhimurium P99 & $6.61 \pm 0.15^{\mathrm{Ab}}$ & $4.89 \pm 0.36^{\mathrm{Bd}}$ \\
Staphylococcus aureus KCCM 11335 & $7.25 \pm 0.05^{\mathrm{Aa}}$ & $6.86 \pm 0.14^{\mathrm{Ba}}$ \\
\hline All values are mean
\end{tabular}

All values are mean \pm standard deviation.

${ }^{A-B}$ The superscript upper-case letters in the same row indicate statistical differences by Student's t-test $(p<0.05)$.

${ }^{a-d}$ The superscript lower-case letters in the same column indicate statistical differences by ANOVA $(p<0.05)$.

\section{Inhibition of adherence of food-borne pathogenic bacte- ria to HT-29 cells}

Adhesion ability of L. plantarum G72 to HT-29 cells was assessed by counting the number of food-borne pathogenic bacteria adhered to HT-29 cells in Table 3. $L$. plantarum G72 inhibited the adherence of food-borne pathogenic bacteria to HT-29, the cell numbers of foodborne pathogenic bacteria ranging from 4.89 to $6.86 \mathrm{Log}$ CFU/ml. L. plantarum G72 inhibited the adherence of food-borne pathogenic bacteria to HT-29 and food-borne pathogenic bacteria showed a decrease compared to nontreatment of L. plantarum G72. The results showed food-borne pathogenic bacteria ranging from 4.89 to 6.86 $\mathrm{CFU} / \mathrm{ml}$. The adherence of $E$. coli ATCC 25922 and $S$. aureus KCCM 11335 decreased 0.17 Log CFU/ml and 0.39 Log CFU/ml, especially, the adherence of S. Typhimurium P99 decreased remarkably (1.72 Log CFU/ml). However, L. monocytogenes ATCC 15313 increased 0.67 Log CFU/ml, although antimicrobial activity of $L$. plantarum G72 against L. monocytogenes showed in Table 2. This result was influenced by physical factors such as auto-aggregation, co-aggregation, and hydrophobicity. Additionally, inhibition of adherence of $S$. Typhimurium P99 in the presence L. brevis KU15006 to HT-29 cells with an $85.18 \%$ reduction in cell number has been reported [7]. Weissella cibaria JW15 exhibited a $55.43-69.44 \%$ inhibition in adhesion of food-borne pathogenic bacteria [22]. In a previous study, Lactococcus lactis $\mathrm{KC24}$, isolated from kimchi, decreased the
Table 4. Production of folate by $L$. rhamnosus GG and $L$. plantarum G72.

\begin{tabular}{cccc}
\hline & \multicolumn{3}{c}{ Samples } \\
\cline { 2 - 4 } & Folate & $\begin{array}{c}\text { L. rhamnosus } \\
\text { GG }\end{array}$ & $\begin{array}{c}\text { L. plantarum } \\
\text { G72 }\end{array}$ \\
\hline $\begin{array}{c}\text { Production of folate } \\
(\mathrm{ng} / \mathrm{ml})\end{array}$ & $80.21 \pm 2.34^{\mathrm{a}}$ & $50.1 \pm 1.26^{\mathrm{c}}$ & $55.5 \pm 0.21^{\mathrm{b}}$ \\
\hline
\end{tabular}

All values are mean \pm standard deviation.

a-cThe superscript letters in the same row indicate statistical differences $(p<0.05)$.

adhesion of L. monocytogenes and $S$. aureus to Caco-2 cells [26]. Therefore, L. plantarum G72 could also inhibit the adherence of food-borne pathogenic bacteria to the GI tract.

\section{Production of folate}

Production of folate was measured using a minor method with folic acid ELISA kit. Folate is one of the most important components for proper functioning of our body. Folate cannot be synthesized by the human body and has to be obtained through dietary supplements and fortified foods [15, 27]. Production of folate by L. plantarum G72 and LGG showed a $50.1 \mathrm{ng} / \mathrm{ml}$ and $55.55 \mathrm{ng} / \mathrm{ml}$ in Table 4 . When compared to 2 strains, it was confirmed that the production of folate showed little difference. Many studies have reported that lactic acid bacteria strains can produce folates [15]. One research indicated that L. sakei strains (CRL 2209 and 2210) produced higher folate (730-1,484 ng/g) [15]. L. rhamnosus GG IFM4, among the isolated strains, determined that production of folate showed the highest level $(35 \mathrm{ng} / \mathrm{ml})$ [28]. In addition, Lactobacillus fermentum 8.2 and $L$. plantarum 6.2 isolated from fermented food showed the highest production levels of folate (97 and $93 \mathrm{ng} / \mathrm{ml}$ ) [29]. Generally, Lactobacillus sp. cannot produce folate, however, L. plantarum, L. lactis, and Streptococcus thermophilus are regarded as good functional substances for production of folate [14]. These results seem to show that L. plantarum G72 could be used as health food substance in our body.

\section{Short-chain fatty acids analysis}

SCFAs are of vital importance in the food industry to improve food quality and safety [30]. L. plantarum G72 produced SCFAs such as formic acid, lactic acid, acetic 
Table 5. Production of short-chain fatty acids (SCFAs) by L. rhamnosus GG and L. plantarum G72 in MRS broth.

\begin{tabular}{lccccc}
\hline \multirow{2}{*}{ Microorganisms } & \multicolumn{5}{c}{ Short-chain fatty acids $(\mathrm{mg} / \mathrm{kg})$} \\
\cline { 2 - 6 } & Formic acid & Lactic acid & Acetic acid & Propionic acid & Butyric acid \\
\hline L. rhamnosus GG & $1,319.29 \pm 75.06^{\mathrm{BC}}$ & $10,026.64 \pm 264.66^{\mathrm{Ba}}$ & $743.66 \pm 98.88^{\mathrm{Bd}}$ & $2,001.57 \pm 201.61^{\mathrm{Ab}}$ & $126.73 \pm 98.92^{\mathrm{Be}}$ \\
L. plantarum G72 & $2,162.20 \pm 122.40^{\mathrm{Ab}}$ & $11,176.73 \pm 531.63^{\mathrm{Aa}}$ & $1,380.70 \pm 75.65^{\mathrm{Ac}}$ & $82.81 \pm 7.94^{\mathrm{Bd}}$ & $340.99 \pm 3.20^{\mathrm{Ad}}$ \\
\hline
\end{tabular}

All values are mean \pm standard deviation.

${ }^{A-B}$ The superscript upper-case letters in the same column indicate statistical differences by Student's t-test $(p<0.05)$.

${ }^{a-e}$ The superscript lower-case letters in the same row indicate statistical differences by ANOVA $(p<0.05)$.

acid, propionic acid, and butyric acid in MRS broth which was detected through the HPLC chromatography in Table 5. SCFAs play an important role in the gastrointestinal condition to protect against food-borne pathogenic bacteria [31]. In this study, SCFAs including formic acid, lactic acid, acetic acid, propionic acid, and butyric acid were produced in the range $82.81 \mathrm{mg} / \mathrm{kg}$ to $11,176.73 \mathrm{mg} / \mathrm{kg}$. Especially, lactic acid was the most abundant SCFA produced by L. plantarum G72 and LGG $(11,176.73 \mathrm{mg} / \mathrm{kg}$ and $10,026.64 \mathrm{mg} / \mathrm{kg})(p<0.05)$. One study indicated that the production of lactic acid by L. plantarum and Lactobacillus acidophilus was 509.40 $\mathrm{mg} / \mathrm{l}$ and $515.09 \mathrm{mg} / \mathrm{l}$, respectively [30]. It has been demonstrated that $L$. plantarum produced $6.08 \mathrm{~g} / \mathrm{l}$ of lactic acid [32]. W. cibaria JW15 produced $12.60 \mathrm{~g} / \mathrm{l}$ of lactic acid similar to our results [22]. This study demonstrated that the production of butyric acid by $L$. plantarum (340.99 mg/kg) was higher than that of LGG (126.73 mg/ $\mathrm{kg}$ ). The acid of intestinal bacteria could convert sugar, amino acid, and alcohols to propionic acid or butyric acid [33]. A previous study has reported that butyric acid exhibits some therapeutic effects in intestinal diseases and colon cancer [34]. Therefore, L. plantarum G72 might help to improve the gastrointestinal condition by producing SCFAs.

In this study, L. plantarum G72 isolated from kimchi demonstrated potential probiotic strain through antimicrobial activity, inhibition of adherence of food-borne pathogenic bacteria to HT-29 cells, production of folate, and production of SCFAs for pregnant women. We indicated that L. plantarum G72 should be used as safe probiotic strains by confirming no hemolysis effect, high antimicrobial activity, and inhibition of adherence of food-borne pathogenic bacteria to HT-29 cells as safe organism for human health. In addition, L. plantarum G72 could be helped for human as functional effects including production of folate and SCFAs. Therefore, $L$. plantarum G72 may be useful as a potential probiotic and can be applied in health industry.

\section{Conflict of Interest}

The authors have no financial conflicts of interest to declare.

\section{References}

1. Butel MJ. 2014. Probiotics, gut microbiota and health. Med. Mal. Infect. 44: 1-8.

2. FAO/WHO. 2002. Report of a Joint FAO/WHO working group on drafting guidelines for the evaluation of probiotics in food, London, Ontario, Canada.

3. Jørgensen JN, Laguna JS, Millán C, Casabuena O, Gracia Ml. 2016. Effects of a Bacillus-based probiotic and dietary energy content on the performance and nutrient digestibility of wean to finish pigs. Anim. Feed Sci. Technol. 221: 54-61.

4. Gbassi GK, Vandamme T, Yolou FS, Marchioni E. 2011. In vitro effects of $\mathrm{pH}$, bile salts and enzymes on the release and viability of encapsulated Lactobacillus plantarum strains in a gastrointestinal tract model. Int. Dairy J. 21: 97-102.

5. Jeon HL, Yang SJ, Son SH, Kim WS, Lee NK, Paik HD. 2018. Evaluation of probiotic Bacillus subtilis P229 isolated from cheonggukjang and its application in soybean fermentation. LWT - Food Sci. Technol. 97: 94-99.

6. Jang HJ, Song MW, Lee NK, Paik HD. 2018. Antioxidant effects of live and heat-killed probiotic Lactobacillus plantarum Ln1 isolated from kimchi. J. Food Sci. Technol. 55: 3174-3180.

7. Son SH, Jeon HL, Jeon EB, Lee NK, Park YS, Kang DK, et al. 2017. Potential probiotic Lactobacillus plantarum Ln4 from kimchi: Evaluation of $\beta$-galactosidase and antioxidant activities. LWT Food Sci. Technol. 85: 181-186.

8. Jang HJ, Lee NK, Paik HD. 2019. Probiotic characterization of Lactobacillus brevis KU15153 showing antimicrobial and antioxidant effect isolated from kimchi. Food Sci. Biotechnol. 28: 15211528.

9. Jeon HL, Lee NK, Yang SJ, Kim WS, Paik HD. 2017. Probiotic characterization of Bacillus subtilis P223 isolated from kimchi. Food Sci. Biotechnol. 26: 1641-1648.

10. Valero-Cases E, Frutos MJ. 2015. Effect of different types of encapsulation on the survival of Lactobacillus plantarum during 
storage with inulin and in vitro digestion. LWT - Food Sci. Technol. 64: 824-828.

11. Kodi C, Gothandam KM, Prabakaran G. 2015. Identification and characterization of folic acid producing potential starter for curd fermentation. Int. J. Curr. Microbiol. Appl. Sci. 4: 118-130.

12. Maldonado E, López Y, Herrera M, Martínez-Sanz E, MartínezÁlvarez C, Pérez-Miguelsanz J. 2018. Craniofacial structure alterations of foetuses from folic acid deficient pregnant mice. Ann. Anat. 218: 59-68.

13. Zheng L, Huang J, Kong H, Wang F, Su Y, Xin H. 2020. The effect of folic acid throughout pregnancy among pregnant women at high risk of pre-eclampsia: A randomized clinical trial. Pregnancy Hypertens. 19: 253-258.

14. Tarrah A, Castilhos JD, Rossi RC, Duarte VDS, Ziegler DR, Corich V, et al. 2018. In vitro probiotic potential and anti-cancer activity of newly isolated folate-producing Streptococcus thermophilus strains. Front. Microbiol. 9: 2214.

15. Mosso AL, Jimenez ME, Vibnolo G, LeBlanc JG, Samman NC. 2018. Increasing the folate content of tuber based foods using potentially probiotic lactic acid bacteria. Food Res. Int. 109: 168174.

16. Rossi M, Amaretti A, Raimondi S. 2011. Folate production by probiotic bacteria. Nutrients 3: 118-134.

17. Ríos-Covián D, Ruas-Madiedo P, Margolles A, Gueimonde M, De los Reyes-Gavilán CG, Salazar N. 2016. Intestinal short chain fatty acids and their link with diet and human health. Front. Microbiol. 7: 185.

18. Darendelioglu E, Ciftci M, Baydas G. 2017. The apoptotic effects of SCFAs from Lactobacillus reuteri on (HT-29) human colon cancer cells. Tr. J. Nature Sci. 6: 11-19.

19. Morrison DJ, Preston T. 2016. Formation of short chain fatty acids by the gut microbiota and their impact on human metabolism. Gut Microbes 7: 189-200.

20. Joseph N, Vasodavan K, Saipudin NA, Yusof BNM, Kumar S, Nordin SA. 2019. Gut microbiotia and short-chain fatty acids (SCFAs) profiles of normal and overweight school children in Selangor after probiotics administration. J. Funct. Foods 57: 103-111.

21. Liu T, Li J, Liu Y, Xiao N, Suo H, Xie K, et al. 2012. Short-chain fatty acids suppress lipopolysaccharide-induced production of nitric oxide and proinflammatory cytokines through inhibition of NFKB pathway in RAW264.7 cells. Inflammation 35: 1676-1684.

22. Yu HS, Lee NK, Choi AJ, Choe JS, Bae CH, Paik HD. 2019. Antagonistic and antioxidant effect of probiotic Weissella cibaria JW15.
Food Sci. Biotechnol. 28: 851-855.

23. Pieniz S, Andreazza R, Anghinoni T, Camargo F, Brandelli A. 2014. Probiotic potential, antimicrobial and antioxidant activities of Enterococcus durans strain LAB18s. Food Control 37: 251-256.

24. Kumar A, Kumar D. 2015. Characterization of Lactobacillus isolated from dairy samples for probiotic properties. Anaerobe 33: 117-123.

25. Mohanty D, Panda S, Kumar S, Ray P. 2019. In vitro evaluation of adherence and anti-infective property of probiotic Lactobacillus plantarum DM69 against Salmonella enterica. Microb. Pathog. 126: 212-217.

26. Lee NK, Han KJ, Son SH, Eom SJ, Lee SK, Paik HD. 2015. Multifunctional effect of probiotic Lactococcus lactis KC24 isolated from kimchi. LWT - Food Sci. Technol. 64: 1036-1041.

27. Radziejewska A, Chmurzynska. 2019. Folate and choline absorption and uptake: Their role in fetal development. Biochimie 158: 10-19.

28. Panda SH, Das S, Bal P, Panda SK, Goli JK, Mohanty N. 2018. Characterization of novel folate producing Lactobacillus rhamnosus and its appliance in fortification of ragi (Eleusine coracana) guel. Food Biosci. 21: 100-106.

29. Greppi A, Hemery Y, Berrazaga I, Almaksour Z, Humblot C. 2017. Ability of lactobacilli isolated from traditional cereal-based fermented food to produce folate in culture media under different growth conditions. LWT - Food Sci. Technol. 86: 277-284.

30. Özcelik S, Kuley E, Özogul F. 2016. Formation of lactic, acetic, succinic, propionic, formic and butyric acid by lactic acid bacteria. LWT - Food Sci. Technol. 73: 536-542.

31. Argyri AA, Zoumpopoulou G, Karatzas KAG, Tsakalidou E, Nychas GJE, Panagou EZ, et al. 2013. Selection of potential probiotic lactic acid bacteria from fermented olives by in vitro test. Food Microbiol. 33: 282-291.

32. Vodnar DC, Paucean A, Dulf FV, Socaciu C. 2010. HPLC characterization of lactic acid formation and FTIR Fingerprint of probiotic bacteria during fermentation processes. Not. Bot. Horti Agrobot. Cluj-Napoca 1: 109-113.

33. Cibis KG, Gueipel A, König H. 2016. Isolated of acetic, propionic and butyric acid-forming bacteria from biogas plants. J. Biotechnol. 220: 51-63.

34. Jiang L, Fu H, Yang HK, Xu W, Wang J, Yang ST. 2018. Butyric acid: Applications and recent advances in its bioproduction. Biotechnol. Adv. 36: 2101-2117. 